\title{
The Role of Theory in Empirical L2 Research on Task-Based Language Teaching for Young L2 Learners
}

\author{
Ashley Beccia \\ Teachers College, Columbia University
}

\section{INTRODUCTION}

Task-Based Language Teaching (TBLT) is purportedly the only L2 pedagogy rooted in SLA theory and research and is unique in its psycholinguistic, ecological and pedagogical validity. Theoretical entities such as Processability Theory (Pienemann \& Lenzing, 2020), the cognitiveinteractionist approach (Gass \& Mackey, 2020), and emergentism (O’Grady, 2008) undergird TBLT. Overarching the pedagogy is the metatheory of Complex and Dynamic Systems Theory (Sabah, 2018). Nevertheless, empirical studies on TBLT, especially those on children, seldom engage with the full range of these theoretical entities. An emerging trend in this research domain is that one theoretical entity in particular, the Interaction Hypothesis (Long, 1996), has been used to frame studies (e.g., Azkarai \& Oliver, 2019) and to interpret the results of studies (e.g., Newton \& Bui, 2017) on TBLT for young L2 learners.

This forum will explore the extent to which theory has played a role in empirical research on TBLT for young L2 learners and highlight opportunities that exist for future research. To begin, the most relevant theoretical entities to TBLT will be introduced. This theoretical background will set the stage for the subsequent section - a review of three empirical studies on task-based learning with young L2 learners: Newton and Bui (2017), Zhu (2020), and Azkarai and Oliver (2019). Then, the three studies are discussed with regard to the role theory plays. Finally, some trends that come to light through the review of the studies are identified, and arguments are made vis-à-vis the need for more theory-driven, principled approaches to the empirical research on TBLT with children.

\section{TBLT AND ITS THEORETICAL TENETS}

At the core of TBLT is the idea that L2 acquisition can be facilitated through learners' completion of communicative tasks resembling those that are realized in the real world (Ellis, 2003; Long, 2015). Through the dual use of tasks as the basic structural unit of the syllabus and vehicle for instruction, TBLT fosters organic, contextualized language use as permitted by the learner's current stage of development. In other words, learning happens according to the learner's internal syllabus (Corder, 1967). Put yet another way, learning in TBLT happens as per the learner's developmental readiness to process certain linguistic forms.

This aligns with insight gleaned from Processability Theory (Pienemann \& Lenzing, 2020), namely that a learner may only process forms that their linguistic processor can handle. The psycholinguistic constraints placed on the L2 learner determine what forms can be taught to/learned by a given learner at a certain point in time. As tasks are completed, language is produced spontaneously by the learner, whose production is constrained by their internal

(C) 2021 Beccia. This is an open access article distributed under the terms of the Creative Commons Attribution License, which permits the user to copy, distribute, and transmit the work provided that the original authors and source are credited. 
learning mechanism. Allowing the learner to naturally progress through the developmental stages stipulated by Processability Theory is one way in which TBLT achieves psycholinguistic validity as an L2 pedagogy.

As the learner fills some gap using their own linguistic means to achieve a non-linguistic outcome, meaning is placed at the forefront (Ellis, 2009). Through careful task design, the learner engages in different types of interactions inherently requiring them to negotiate for meaning and utilize feedback to achieve the tasks' goals. In doing so, the learner's attention is drawn to gaps in their interlanguage, pushing them to modify their output. Similarly, in response to breakdowns in communication, the instructor provides focus on form instruction that directs the learner's attention to specific form(s) needed at that point in time. This perspective of L2 development is largely captured by the cognitive-interactionist approach, or the weak version of the Interaction Hypothesis (Gass \& Mackey, 2020).

Another theoretical approach that subserves TBLT is emergentism, which stipulates that general cognitive processes are involved in the construction and use of abstract mental representations, including linguistic ones. These representations are constantly changing provided the continuous L2 environmental input and construction and access of the representations. Thus, the learner's communicative experiences with the L2 plays a central role in their interlanguage development (O'Grady, 2008). By engaging the learner in pedagogic tasks that resemble real-world tasks, TBLT provides ways to authentically experience and use the L2. Overall, language use resembles that of the real world, an indicator of the ecological validity TBLT achieves.

In experiencing the L2 during task-based learning, the learner is exposed to L2 input holistically, as opposed to bits and pieces of it. Given that language, the language learner, and language development are interconnected, complex and dynamic systems, it is essential that language learning is understood from a systems perspective. Since L2 input presented to the learner in TBLT is kept intact, the learner is required to analyze the whole of the L2 for themself, setting the approach apart from traditional approaches in which the teacher presents the L2 in an atomistic and linear fashion to the learner, who is expected to synthesize parts of L 2 in a cumulative way. The essence of this distinction was captured in early research on TBLT by Long and Crookes (1992), who distinguished between the synthetic syllabi used in traditional instruction and the analytic syllabi used in TBLT.

In TBLT, the input the learner receives is not only authentic and 'kept whole,' but also of particular relevance to the specific learner. It is through authentic, relevant language use that the learner prepares themself for real-world linguistic demands and develops functional use of the L2. A crucial procedural step in TBLT is relating tasks and learning to a particular set of learners by conducting a needs analysis prior to creating the task-based syllabus. After the administration of the needs analysis, or inventory of the tasks learners complete in their daily lives, target tasks that learners will work toward accomplishing via sequenced pedagogic tasks are derived (Van Avermeat \& Gysen, 2009).

Ultimately, the needs analysis ensures that pedagogic tasks used for instruction are meaningful and authentic for the learner and aimed at developing functional L2 use. This contrasts starkly with traditional methods such as the Presentation, Practice, Production (PPP) method and drill and repetition exercises, which are underpinned by Skill Acquisition Theory (DeKeyser, 1998) and behaviorism (Bloomfield, 1933) respectively. Traditional methods are ineffective in functional L2 development. One major issue with these methods is that developmental readiness of the learner is not taken into consideration, and linguistic units, as 
opposed to acquisitional units (Long \& Crookes, 1992), are taught linearly to the learner, regardless of readiness. While linguistic units refer to those artificially contrived by teachers and linguists, acquisitional units refer to the elements of language that learners psycholinguistically process and acquire. As such, traditional methods, which rely on linguistic units taught via synthetic syllabi, lack psycholinguistic validity.

Within the domain of task-based teaching, researchers have taken different theoretical positions, resulting in two strands of the pedagogy: the strong form and weak form. Those who advocate for strong-form TBLT take the view that there is either (1) no interface between explicit and implicit knowledge, meaning that knowledge learned explicitly cannot be converted into implicit knowledge and vice versa, or (2) a weak interface between explicit and implicit knowledge, meaning that implicit knowledge is primary but may coexist with and contribute to explicit knowledge. Both of these views contrast with the position assumed by weak-form taskbased teaching advocates, who posit that explicit knowledge is a source of implicit knowledge, and, as such, explicit knowledge is the starting point for L2 instruction. Such a position is also taken by proponents of traditional pedagogies such as the PPP method, which begins with the explicit presentation of linguistic forms, which are assumed to be converted to implicit knowledge via practice (Ellis \& Shintani, 2013).

In TBLT research, strong- versus weak-form positions can often be identified by the theoretical entities cited, or not cited, by researchers. The salience of the stances taken by TBLT researchers and the role played by theory in empirical research on TBLT varies. Whereas some researchers make overt reference to the theoretical stances and/or entities in their studies, others allude to theory, or make no connection at all to theory. The strong or weak position taken may also be identified through the conceptualization and operationalization of task-based teaching within studies.

As will be shown in the following section, studies on TBLT, including those with young learners, demonstrate the differential role that theory plays in empirical SLA research. Specifically, the next section reviews three studies on TBLT for child L2 learners: Newton and Bui (2017), Zhu (2020), and Azkarai and Oliver (2019). This will be followed by a discussion of the role theory plays in empirical L2 research on TBLT for young learners.

\section{EMPIRICAL RESEARCH ON TBLT FOR YOUNG L2 LEARNERS}

Newton and Bui (2017) sought to compare the effectiveness of the PPP method and TBLT with third- and fourth-grade L2 learners in Vietnam. The researchers argued that TBLT has been under-researched in the primary school setting, and they emphasized the importance of the needs analysis as a procedural step in TBLT, as per Long's (2015) conceptualization of the pedagogy. The researchers also contended that TBLT pivots on the communicative tasks being derived from the needs analysis, setting this "stronger" approach to TBLT apart from weak-form approaches, which often rely on textbooks for predetermined sequences of task-like activities. To investigate the PPP method versus TBLT in the primary school context, the researchers conducted a two-stage study. First, they observed how seven EFL teachers in Vietnam implemented the PPP method in their prescribed textbook with their classes. Shortly afterwards, the teachers engaged in stimulated recall interviews with the researchers, in addition to interviews conducted a few days later. This stage served to gauge the teachers' cognitions toward the textbook and PPP method. 
In the second stage, the researchers recreated PPP lessons from the textbook to reflect TBLT and briefed three of the teachers on implementing the task-based lessons. Such revised lessons were based on Ellis's (2003) definition of task and Willis and Willis's (2007) TBLT cycle design, including an input-based task in the 'pre-task' stage, an information gap in the 'main task' stage, and focus on form in the 'post-task' stage. Next, the three teachers were observed implementing the task-based lessons to a total of 18 student pairs in fourth grade. Finally, interviews were conducted with the teachers, as well as a selected group of learners, in order to gauge their attitudes towards task-based teaching and learning.

Newton and Bui found that, during the first stage, teachers generally followed the textbook PPP sequences closely, despite some adding more commutative, task-like activities to the presentation and production stages of the PPP (textbook) lessons in an attempt to compensate for its evident shortcomings - namely, that it did not promote functional use of the L2. Nevertheless, some sentiments the teachers expressed toward the PPP method were positive (e.g., some teachers saw the predictability of the PPP as beneficial for teaching and/or learning). With respect to the study's second stage, the implementation of the revised, task-based lessons yielded positive teacher attitudes toward the task-based approach and benefited the learners in a multitude of ways (e.g., pushing their output and encouraging the negotiation of meaning). In discussing these benefits, the researchers referred to the collaborative scaffolding that took place among learners as they completed the tasks.

Zhu (2020) investigated the implementation of what she called "TBLT" with EFL learners in a Chinese primary school, focusing on one novice teacher working with second grade students. Interested in investigating how the teacher could be supported in implementing TBLT in her teaching context, the goal of the six-week action research was to study how engaging the teacher in two teaching cycles - involving lesson planning, implementation, evaluation and reflection - would impact her teaching and her students' learning. The hypothesis was that the teacher's implementation of TBLT would improve from the first to the second teaching cycle, during both of which support from the researcher was continuously provided. Accordingly, learners in the second cycle of TBLT might acquire more words of the target vocabulary items as a result of the teacher's improved practice.

During the lesson planning stages of the two cycles, the teacher and researcher worked together to develop task-based lessons (with pre-task, task, post-task and homework components) that targeted the vocabulary items from the traditional textbook lesson about the same topic: restaurants. Each of two implementations of task-based lessons was given to different classes. To measure the target forms that learners in the two classes acquired, the teacher and researcher measured learners' recognition and production of the words before and after task-based instruction. Other data gathered were qualitative and came from interviews with the novice teacher and researcher, interviews with students, and discussions among the teacher and her colleagues.

During the teacher's implementation of TBLT, learners engaged in tasks designed to be more hands-on and interactive than the mandatory textbook activities. For example, learners listened to a song about Yummy Restaurant and made posters displaying the items the restaurant sells, which replaced listen and repeat drills from the textbook. On some occasions, the tasks that the teacher and researcher had planned together were changed by the teacher during implementation. For instance, during the implementation stage of the first cycle, the teacher changed one of the tasks to a listening exercise during which students listened to a pre-recorded dialogue and answered multiple choice questions. During both cycles, the teacher produced non- 
authentic constructions (e.g., 'to like doing something' construction in the context of ordering food) as a result of the linguistic structure prescribed for the same topic in the textbook used for traditional instruction.

The findings were that students in the second cycle of TBLT outperformed those who participated in the first cycle, who outperformed those in a control class, on measures of vocabulary comprehension and production. Students in the second cycle condition were also more successful at completing the four tasks that comprised their task-based lesson, indicating that the tasks in the second cycle were more appropriately designed than those in the first cycle. This is possibly the result of the teacher having reflected on and evaluated the implementation of tasks in the first cycle and improving the tasks for the second cycle accordingly. Lastly, the findings from the interview data were that the task-based lesson yielded positive attitudes from the teacher and her students.

Azkarai and Oliver (2019) studied the effects of feedback provided to seven- and eightyear-old learners while they completed tasks. As 12 student pairs in the EFL (Spain) context and 12 student pairs in the ESL (Australia) contexts engaged in a 'spot-the-difference' task two times, negative feedback was provided in the form of recasts and negotiation of meaning strategies (e.g., clarification requests). In introducing this empirical study and the rationale behind it, the researchers referred to key constructs in the cognitive-interactionist theory, such as interaction, negotiation of meaning, and feedback, though never overtly referenced the theory itself.

After the performances of the tasks were audio-recorded, transcribed, and coded for errors, the researchers analyzed the data and found that a significantly greater number of utterances were produced by the ESL learners as compared to the EFL learners. They also found an increase, although not statistically significant, from the first to the second task in the number of utterances produced by the ESL learners. These trends were attributed to the L2 proficiency of the learners in the two contexts. Additionally, differences between the participant groups were evident in the production of errors and use of negative feedback (recasts and negotiation of meaning strategies) provided during both second task performances. Overall, learners in the EFL group made more errors than the ESL group, and learners, especially those in the ESL group, were more likely to use negative feedback during the second completion of the tasks. The ESL learners also used different strategies for the negotiation of meaning (e.g., requesting information and self-repetition) from the EFL learners, who most frequently used lexical searches (i.e., clarification requests about a specific word) during both task completions.

According to Azkarai and Oliver (2019), the study contributed to an understanding of how task repetition and negative feedback can "promote focus on form" in EFL and ESL settings (p. 277), and added empirical support to the growing body of evidence that task repetition benefits L2 learners, including children. Further, the study notably investigated the differences between the effects of such treatments on learners in an EFL versus an ESL setting.

\section{DISCUSSION}

In combination, the three studies reviewed partially elucidate the role that theory plays in empirical research on TBLT for young L2 learners. Newton and Bui (2017) examined, inter alia, how PPP lessons from textbooks may be recrafted as task-based lessons. This study primarily provided descriptive information regarding how researchers and teachers in one part of the world conceptualized and justified the strong version of the pedagogy, despite missing the target in 
terms of planning for and implementing strong-form TBLT. For example, the researchers cited the importance of needs analyses in a "stronger-form" of TBLT, and yet, the main information gap task in the study was derived from a textbook lesson, rather than a needs analysis. Further, the teachers in the study reported having insufficient time to provide the focus-on-form instruction that was planned for the post-task stage, another indication that the implementation of task-based pedagogy represented a weaker, not a stronger, version of task-based teaching.

Though Newton and Bui (2017) did not directly contribute to our understanding of the effectiveness of strong-form TBLT for young L2 learners, it did shed light on potential TBLT planning and implementation difficulties for researchers and teachers. The study also illustrates the importance of clearly defining constructs in empirical research. For instance, discussing the needs analysis as an essential procedural step in strong-form TBLT, deeming the pedagogy used in the study as a "stronger version of task-based teaching" (p. 263), and then omitting the needs analysis is confusing and attenuates the validity of the construct 'strong-form TBLT.' By including the theoretical entities underpinning the strong version of the pedagogy, in addition to describing the pedagogy itself, the authors may have more consistently defined and operationalized constructs, resulting in more generalizable results.

Additionally, when analyzing the benefits of the task-based lessons implemented in the study, Newton and Bui (2017) discussed constructs such as the negotiation of meaning and scaffolding. These constructs from the Interaction Hypothesis (Long, 1996) are used in a post hoc manner to make meaning of the data: interactions between students as they completed tasks. Azkarai and Oliver (2019) also discussed their research in relation to Long's (1996) Interaction Hypothesis, using the theoretical entity to frame the study itself. The data collected were intended to explore the effects that negative feedback - specifically recasts and negotiation of meaning - had on L2 learners as they engaged in the same task repeated multiple times. However, Newton and Bui (2017) and Azkarai and Oliver (2019) differ in that the former employs the theoretical entity to explain the findings from their study, while the latter uses theory to frame the study itself.

Playing yet another role, the theoretical entities vis-à-vis TBLT in Zhu (2020) are under the surface. Although the researcher acknowledged the empirical support TBLT had received from prior research, referred to "task-based language teaching (TBLT) principles" (p. 2), and warned of the "theory-practice disparity in TBLT-related teacher education" (p.4), Zhu did not identify which theoretical entities support TBLT nor did she conceptually engage with the theoretical basis underlying the pedagogy. In this way, theory did not play a major role in the researcher's exploration of task-based teaching implementation, which, as a result of a feeble theoretical foundation, was not entirely congruent with the theoretical tenets of TBLT as discussed above.

In terms of the lessons that Zhu (2020) and the teacher in her study collaboratively planned, vocabulary words from the traditional textbook are used as target words in the taskbased lesson, making the relevance and authenticity of the target forms questionable. Though traditional exercises were not part of the plan for the task-based lessons, during implementation the teacher included traditional exercises such as listening drills, an approach to language teaching that would likely rely on the assumption there is a strong interface between explicit and implicit knowledge. To attend to these issues, the researcher could have taken a more theorydriven approach and involved the teacher in more conceptual engagement with the theory underlying TBLT. By strengthening the theory-research-practice connection, teachers will 
develop more psycholinguisitically-plausible practices and most importantly, learners will acquire second languages efficiently and effectively.

The three studies reviewed can be placed along a spectrum according to the extent to which theory drives the research. Whereas some studies use theoretical entities to frame the research itself, others cite theoretical entities after the study has been completed in an attempt to make meaning from the results. Still, other studies allude to the theoretical tenets underlying TBLT without outwardly engaging with the relevant theoretical entities. Overall, it is evident that more theory-driven research in the domain is needed. Such research should not only include bottom-up, exploratory studies, but also top-down validations of the theory-based pedagogy. This will allow researchers to confirm the psycholinguistic and pedagogical validity of TBLT and contribute more generally to our understanding of classroom-based SLA.

\section{CONCLUSION}

Overall, researchers who have studied TBLT with young L2 learners have engaged with the theoretical entities underlying the pedagogy in various ways. In multiple studies, traditional pedagogy permeated task planning and/or implementation. For example, the task-based lessons in Newton and Bui (2017) and Zhu (2020) were based on lessons from traditional textbooks. Since the needs analysis, an essential procedural step for strong-form TBLT, was omitted in both studies, the relevance of the tasks and the learner-centeredness of the approaches come into question. Additionally, instead of taking transparently weak stances on task-based teaching, some researchers (e.g., Newton and Bui) simply mislabeled the approach they took as a 'stronger' form of task-based teaching, again pointing to construct definition issues. One reason the construct 'TBLT' may have been defined variably across studies is that the studies shallowly defined or neglected to define the pedagogy's theoretical tenets. Without using the theoretical entities that subserve TBLT to guide research on the pedagogy, the psycholinguistic, ecological, and pedagogical validity of the pedagogy is at risk of attenuation.

Through the review of the three empirical studies on TBLT for young learners, two patterns have begun to emerge. First, researchers in the domain of TBLT for young L2 learners have seldom evoked the very theoretical entities underpinning TBLT that give rise to its psycholinguistic, ecological and pedagogical validity. Second, it appears that the theoretical entity that has primarily been used to either frame research (e.g., Azkarai and Oliver) or interpret results (e.g, Newton and Bui) in this domain is the Interaction Hypothesis (Long, 1996). Other theoretical entities such as Processability Theory and emergentism were cited neither a priori nor a posteri in the reviewed studies.

There is a need for more theory-driven, principled approaches to the empirical research on TBLT with young L2 learners. Only one of the three studies reviewed, Azkarai and Oliver (2019), used theory to frame the research. One grave consequence of not guiding research with theory can be that constructs are variably defined and operationalized across studies, making findings difficult to compare and generalize. Thus, it is imperative that future research in the domain be guided by the theoretical entities underpinning TBLT, such as Processability Theory, cognitive-interactionist theory, emergentism, and Complex and Dynamic Systems Theory (CDST), to ensure alignment with the pedagogy's key theoretical tenets. In doing so, researchers can empirically validate TBLT, the sole L2 pedagogy based on current theories in SLA. 


\section{REFERENCES}

Azkarai, A., \& Oliver, R. (2019). Negative feedback on task repetition: ESL vs. EFL child settings. The Language Learning Journal, 47(3), 269-280.

https://doi.org/10.1080/09571736.2016.1196385

Bloomfield, L. (1933). Language. New York: Holt.

Corder, S. P. (1967). The significance of learners' errors. International Review of Applied Linguistics and Language Teaching, 5, 161-170.

DeKeyser, R. (1998). Exploring automatization processes. TESOL Quarterly, 30(2), 349-357.

Ellis, R. (2003). Task-based language learning and teaching. Oxford, UK: Oxford University Press.

Ellis, R. (2009). Task-based language teaching: Sorting out the misunderstandings. International Journal of Applied Linguistics, 19(3), 221-246.

Ellis, R., \& Shintani, N. (2013). Exploring language pedagogy through second language acquisition research. ProQuest Ebook Central. https://ebookcentral-proquestcom.tc.idm.oclc.org

Gass, S. \& Mackey, A. (2020). Input, interaction, and output in L2 acquisition. In B. VanPatten, G. Keating, \& S. Wulff (Eds.), Theories in second language acquisition: An introduction (3 ${ }^{\text {rd }}$ ed., pp. 63-82). New York: Routledge.

Long, M. (1996). The role of linguistic environment in second language acquisition. In W. Ritchie, \& T. K. Bhatia (Eds.), Handbook of second language acquisition (pp. 413-468). San Diego, CA: Academic Press.

Long, M. (2015). Second language acquisition and task-based language teaching. Malden, MA: Wiley Blackwell.

Long, M. \& Crookes, G. (1992). Three approaches to task-based syllabus design. TESOL Quarterly, 26(1), 27-56.

Newton, J., \& Bui, T. (2017). Teaching with tasks in primary school EFL classrooms in Vietnam. In M. Ahmadian, \& M. García Mayo (Eds.), Recent perspectives on task-based language learning and teaching (pp. 259-278). Boston: Mouton de Gruyter.

O’Grady, W. (2008). The emergentist program. Lingua, 118(4), 447-464. https://doi.org/10.1016/j.lingua.2006.12.001

Pienemann, M. \& Lenzing, A. (2020). Processability theory. In B. VanPatten, G. Keating, \& S. Wulff (Eds.), Theories in second language acquisition: An introduction $\left(3^{\text {rd }}\right.$ ed., pp. $162-$ 191). New York: Routledge.

Sabah, S. (2018). Differences between task, exercise, and drill in L2 education: A systemsthinking perspective. Advances in Language and Literacy Studies, 9(6), 9-13.

Van Avermaet, P., \& Gysen, S. (2009). From needs to tasks: Language learning needs a taskbased approach." In K. V. Branden, M. Bygate, \& J. M. Norris (Eds.), Task-Based Language Teaching: A reader (Vol. 1, pp. 143-170). Amsterdam: John Benjamins.

Willis, D., \& Willis, J. (2007). Doing task based teaching. Oxford: Oxford University Press.

Zhu, Y. (2020). Implementing tasks in young learners' language classrooms: A collaborative teacher education initiative through task evaluation. Language Teaching Research, 1-22. https://doi.org/10.1177/1362168819894706 
Ashley Beccia is a doctoral student in Applied Linguistics at Teachers College, Columbia University. Specializing in Second Language Acquisition (SLA), her research interests include Task-Based Language Teaching, child SLA, and language play. Correspondence should be sent to E-mail: ajb2301@tc.columbia.edu 